\title{
Out of the darkness: the first comprehensive survey of the Critically Endangered Anjouan Scops Owl Otus capnodes
}

\author{
KATHLEEN E. GREEN, BRONWEN M. DANIEL, SAMUEL P. LLOYD, \\ ISHAKA SAID, AMELAID HOUMADI, DANIEL M. SALIM, \\ SOUFIANI M'MADI, HUGH DOULTON and RICHARD P. YOUNG
}

\begin{abstract}
Summary
Although birds are among the best studied taxa, many of the globally threatened species lack the information required to fully assess their conservation status and needs. One such species is the Anjouan Scops Owl Otus capnodes which was presumed extinct until its rediscovery to science in 1992. Based on the limited extent and decline of the moist forests in the highlands of Anjouan in the Comoro Islands, a population size of only 100-200 pairs was estimated and the species was classified as 'Critically Endangered'. The current study is the first comprehensive survey ever conducted on this species, and aimed to establish the current distribution and population size. Point counts with distance sampling were conducted across the agroforestry and forest zones of Anjouan in both a dry and wet season. A niche suitability model predicted the species distribution to be wider than expected with owls observed as low as $300 \mathrm{~m}$ altitude and in highly modified agroforestry habitats. However, the encounter rate in natural relatively undisturbed forest was significantly greater than in other habitats. The wider than expected geographic range of O. capnodes supports a possible downlisting of this species on the IUCN Red List to 'Endangered'. Population size was found to be far greater than previously thought, at approximately 3,450 individual owls in the dry season and 5,450 in the wet season. These results show the importance of investing in robust surveys of poorly known and cryptic bird species, and provide up to date and important information for landscape scale conservation planning in the Comoros Islands.
\end{abstract}

\section{Introduction}

Birds are the best studied vertebrate class, yet essential information for assessing conservation status and needs is still not available for a considerable number of species (BirdLife International 2008a, Vié et al. 2009). Sixty three bird species are listed as 'Data Deficient' on the IUCN Red List of Threatened Species, of which $17(27 \%)$ have almost no information available as a result of few or no recent records. Of the 190 species listed as 'Critically Endangered', 30 (16\%) currently have no known population size, and $15(8 \%)$ are listed as possibly extinct (Tobias et al. 2006, Butchart 2007, BirdLife International 2008b). To address these knowledge gaps for the 'Critically Endangered' species, priority research areas have been identified as estimating population size, trends, and distribution for $77 \%$ of the species, conducting ecological research for $35 \%$ of species, and $19 \%$ requiring greater knowledge of threats (BirdLife International 2008b).

Examples of poorly known species which are listed as 'Critically Endangered' by IUCN (2014) are the three scops owls endemic to the Comoro Islands: the Anjouan Scops Owl Otus capnodes, Mohéli Scops Owl O. moheliensis, and Karthala Scops Owl O. pauliani on Grande Comore 
(Butchart 2007). Although the taxonomy of many Otus species remains uncertain due to the scarcity of records (Widodo et al. 1999, Rasmussen et al. 2000, Miranda et al. 2011), the morphology, vocalisations and genetic differences of these species supports their classification as distinct species of differing evolutionary lineages (Fuchs et al. 2008). The discovery of these species was relatively recent: O. pauliani was first described in 1958 from a feather used in the lining of a nest (Benson 1960, Herremans et al. 1991), O. moheliensis was first encountered in 1996 (Lafontaine and Moulaert 1997) and O. capnodes was rediscovered in 1992, having previously been thought extinct (Safford 1993). Detailed morphology and vocalisations have been described (Benson 1960, Herremans et al. 1991, Safford 1993, Lafontaine and Moulaert 1997), but population sizes and distributions are poorly known. All three species were originally thought to be restricted to high altitude forest zones (Herremans et al. 1991, Safford 1993, Lafontaine and Moulaert 1997), however O. moheliensis and O. capnodes have recently been detected at lower elevations and in highly modified habitats (Doulton et al. 2006, Lloyd 2010, K. Green unpubl. data). Population estimates based on the remaining area of suitable habitat on each island were calculated as 1,00o pairs for $O$. pauliani (Herremans et al. 1991), 400 individuals for O. moheliensis (Lafontaine and Moulaert 1997), and 100-200 pairs (Safford 1993) 50 individuals (Moorcroft et al. 1995), or 4,950 individuals (Lloyd 2010) for O. capnodes. Even less information is available on the ecology and behaviour of these species due to a lack of field research, the difficult terrain of the islands, and the nocturnal and elusive natures of the species.

The Comoros Islands are situated in the Western Indian Ocean, equidistant from Mozambique and Madagascar. These small, densely populated islands have undergone dramatic changes in their natural landscape, and this has resulted in considerable pressures on a range of endemic fauna. The Comoros are one of the poorest countries in the world, with at least $46 \%$ of the population subsisting on less than $\$_{1.25}$ a day (UN 2010). An estimated $72 \%$ of the population live rurally (FAO 2010) and are directly dependent on agriculture and fisheries. These factors, combined with very limited national-level capacity for environmental governance and no terrestrial protected areas, have led to extensive deforestation in the 35 years since independence from French rule. Between 2000 and 2010, the rate of forest loss was the highest in the world at 9\%; almost double that of the second country listed (FAO 2010). Comorian scops owls are predicted to be at particular risk from these changes in the landscape due to their perceived dependency on forest habitats. Consequently, the conservation of the Comorian forests is listed as one of the top Io global actions to prevent extinctions of 'Critically Endangered' species by Birdlife International (2008b).

This study focused on the Anjouan Scops Owl O. capnodes, in particular the need for improved estimates of population size and distribution. The first comprehensive field survey of O. capnodes was undertaken using nocturnal point counts across potentially occupied habitats on Anjouan, during both the wet and dry seasons. These data were integrated with remotely sensed information on land cover, and a niche suitability model was developed to estimate the total area of potential occupancy and to understand key environmental factors driving this distribution. The results are discussed within the context of future conservation planning and monitoring of the species in Anjouan.

\section{Methods}

\section{Study species}

O. capnodes was first described by Gurney (1889) but the recorded failure to find the species during subsequent expeditions resulted in its presumed extinction, until its confirmed rediscovery to science in June 1992 (Safford 1993). It is a small owl, approximately $20-22 \mathrm{~cm}$ tall and with a wing length of $16-18 \mathrm{~cm}$ (Benson 1960, Safford 1993). Benson (1960) described from specimens two colour phases or morphs: a paler morph with a creamy-grey facial disc and dark surround, and a darker brown morph with less distinct markings (see also Safford 1993). Its distinctive whistle call 
has been described as a di- or tri-syllabic "peeoo" or "peeooee" lasting 0.35-0.51 seconds, with typically three to five calls given at 0.5-1.0 s intervals, and complete vocalisations separated by at least Io s (Safford 1993).

Initially, O. capnodes was described as restricted to above $800 \mathrm{~m}$ altitude and forest- dependent but tolerant of the first stages of degradation (Safford 1993). More recent studies have detected individuals at elevations as low as $300 \mathrm{~m}$ and in modified habitats such as agroforestry plantations and degraded forests (Doulton et al. 2006, Lloyd 2010). Safford (1993) estimated the population size as 100-200 pairs, based on an approximate remaining suitable habitat of $10-20 \mathrm{~km}^{2}$ and territory size being the same as O. pauliani at around 5 ha (Herremans et al. 1991). Moorcroft et al. (1995) estimated a population of 50 individuals based on extrapolation of the density of owls observed to equivalent habitats which were inaccessible. More recently, in a non-peer reviewed thesis, Lloyd (2010) used a combination of a habitat suitability model and distance analysis to estimate a dry season population size of 4,950 individuals.

\section{Study area}

Anjouan is a small volcanic island of $425 \mathrm{~km}^{2}$ situated in the Comoros archipelago, along with Grande Comore, Mohéli, and Mayotte (Figure 1). The island has a tropical climate, with a wet season from November to April. The landscape is made up of steep-sided mountains with deep valleys, the highest point on the island being Mount Ntringui at $1,595 \mathrm{~m}$. Anjouan supports a relatively large human population, with a high density of 446 people $\mathrm{km}^{-2}$ (UNEP 2008). An estimated $114 \mathrm{~km}^{2}$ of natural and degraded forest remains on the island, largely found in the high altitude zones (Green 2013). Land at lower altitudes has been converted for human use, with agroforestry zones at mid-altitudes, and crop plantations closer to the villages which lie along the coasts and in valleys. Considering the previous detection of O. capnodes at $300 \mathrm{~m}$ altitude (Doulton et al. 2006), our surveys focused in the high altitude natural and degraded forest zones descending to mid-low altitude agroforestry areas, from 50-1,330m altitude (Figure 1). Additional exploratory surveys were conducted in the mangrove forests near to Bimbini.

\section{Field surveys}

To take into account the climatic variation, surveying was conducted during the two main seasons: in the dry season from 12 May 2010 to 9 July 2010, and in the wet season from 9 November 2010 to 7 April 2011. Sites were selected to ensure adequate coverage of different habitats and altitudes across the island. However, surveys were restricted to trails due to safety issues resulting from the steep terrain. Survey sites were established using the observers' knowledge of the sites from previously conducted surveys of other species or from prior exploratory visits. With the exception of the mangrove forests, the minimum elevation limit for the field surveys was $300 \mathrm{~m}$, which was defined from previously recorded detection of the species. In some sites, the habitat in the vicinity of $300 \mathrm{~m}$ elevation was extremely degraded. Within the survey sites, the starting point was selected randomly with each subsequent point at least $200 \mathrm{~m}$ apart. A combined total of 443 point counts were conducted (Figure 1); 235 in the dry season across 22 transect locations around Anjouan, and 208 in the wet season across 29 transect locations.

Due to the challenging terrain and elusive nature of the target species, a point count method (Ralph and Scott 1981, Ralph et al. 1995) was employed. At least three observers were present at each point count. Each observer estimated the distance to the owls by ear and mutual agreement gave the final estimate, thus reducing errors in distance estimations. Counts were conducted after dusk, between 18 hoo and 22 hoo, and not during rainy or windy conditions. Points were conducted along transects (Eberhardt 1968, 1978, Gillison and Brewer 1985), with a distance of $200 \mathrm{~m}$ between points to allow data collection with minimal disturbance to neighbouring points. Each count lasted eight minutes; an initial five minutes of passive listening followed by three minutes of call playback. The three minute playback was spilt into $20 \mathrm{~s}$ of vocalisation and $20 \mathrm{~s}$ of silence 


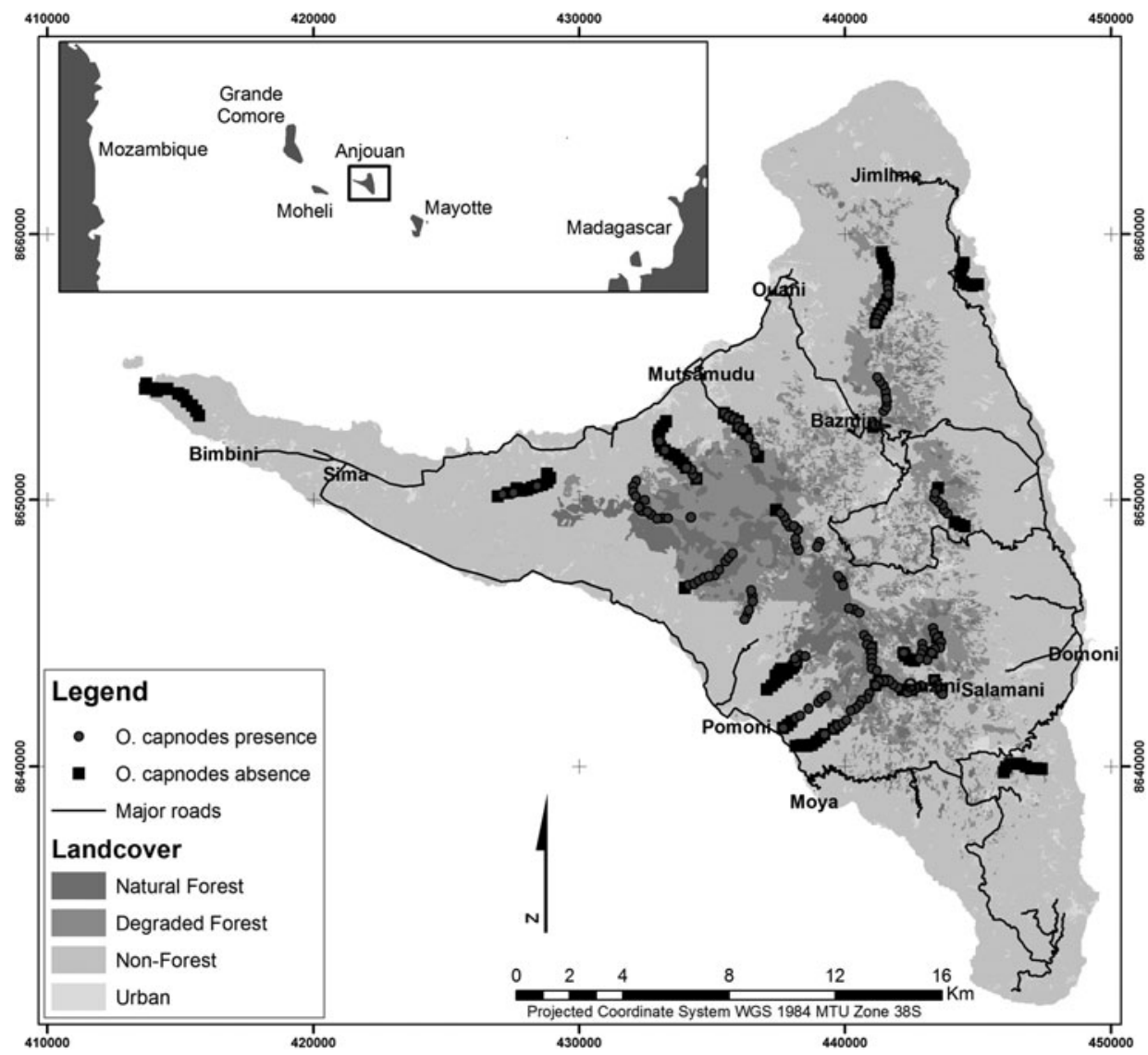

Figure 1. Locations of the point counts surveyed across Anjouan overlaid on a land-cover map (Green 2013). Presence of Otus capnodes is shown by red circles and blue squares show where no individuals were observed. The inset shows the location of Anjouan in the Comoros Islands in the western Indian Ocean.

to imitate the natural vocalisation of the species which has an interlude between calling periods. This also aided data collection as it was easier to identify the direction and distance of vocalising individuals during the silent interlude. If more than one owl was heard calling from the same position, then the total number of owls was recorded.

\section{Data analysis and modelling}

Using the presence observations made during these surveys the extent of occurrence of O. capnodes was calculated using a minimum convex polygon. Statistical analyses of habitat associations were conducted in R2.I1.I (R Core Development Team 2010), using the "glim" package. A Poisson distributed generalised linear model (GLM) was used to assess whether the number of owls observed in each habitat was significantly different. Four categories of habitat were employed based on floral species present and the level of human disturbance: natural forest, degraded forest, agroforestry and non-forest. The presence/pseudo-absence rates in different habitats were compared using a binomial GLM. Only observations made 
during passive listening were used for habitat association analyses to avoid potential bias from owl movements towards the playback vocalisation.

A maximum entropy (MaxEnt) (Philips et al. 2006) approach was taken to model niche suitability for O. capnodes. The MaxEnt model analytically integrates species presence data with environmental data to predict distribution over a given area. This method was chosen as it has been found to perform consistently well when tested across a range of ecological datasets, even with a low number of presence points (Hernandez et al. 2006, Pearson et al. 2007, Wisz et al. 2008).

A total of seven environmental variables were chosen for the model: elevation, aspect, slope, distance from rivers, distance from roads and urban areas, distance from forest, and habitat. These variables were assumed to contribute towards determining niche suitability by their relationships with habitat characteristics, resource availability, temperature, and levels of human disturbance. 'Elevation' was taken from a $30 \mathrm{~m}$ resolution digital elevation model (DEM) (asterweb.jpl.nasa. gov/gdem.asp). From the DEM, 'slope' and 'aspect' (East to West) were derived using ArcGIS Spatial Analyst. The DEM was also used to identify the location of rivers, using flow accumulation, and from this the variable 'distance from rivers' was created. Google Earth and groundtruthing data were used to manually digitise roads and urban areas. This enabled the creation of the variables 'distance from roads and urban areas', which took into account the steepness of the slopes (i.e. non-Euclidean distance). The final environmental variables were 'distance from forest' and 'habitat'. Four categories of habitat were employed based on floral species present and the level of human disturbance: natural forest, degraded forest, agroforestry, and non-forest. These variables were derived from an object based classification of both $5 \mathrm{~m}$ resolution RapidEye and $2 \mathrm{~m}$ resolution GeoEye imagery, using Definiens eCognition software (Green 2013). Distance from forest was calculated as the distance from the core areas of natural and degraded forest identified in the habitat layer and assessed using Patch Analyst (Rempel et al. 2012).

Model performance was examined using the area under the curve (AUC) of the receiver operating characteristic (ROC) and with a jack-knife test of variable importance. The split sample settings which resulted in the best model performance (as determined by ROC), were $70 \%$ training data and $30 \%$ test data, and a regularisation multiplier of one. The model output of probable chance that the habitat in a particular pixel was suitable for owls, was re-scaled into two zones of habitat suitability. Re-scaling was based on the equal training sensitivity and specificity threshold, which was used to define the two bands. Thus, 'low' suitability regions incorporated all areas with model output probabilities of between o and o.34, and 'high' suitability regions incorporated all areas with model output probabilities 0.34 and 1 . The estimated area of occupancy of the species was calculated from the results of the niche suitability model and used to define the survey area for the Distance analysis.

Population size of O. capnodes was estimated using Distance 6.o software (Buckland et al. 1993, Thomas et al. 2010). The sampling unit for the analysis was transect rather than point count because points were placed systematically along a transect and were thus not statistically independent. Only data from point counts that fell within the estimated area of occupancy were used in the analysis; 154 point counts were used, with approximately 260 owls recorded. Observations from only the passive listening period of the count were used in the Distance analysis, with the largest $10 \%$ of all estimated distances discarded in line with the recommendations of Buckland et al. (1993). Post-stratification was conducted per season with a global detection function and density estimate calculated using the mean of the seasons. The data were split into distance intervals of o-15 $\mathrm{m}, 15-35 \mathrm{~m}, 35-55 \mathrm{~m}$, and 55-100 $\mathrm{m}$. These were deemed sufficiently large to minimise the effect of possible errors in the radial distances estimated in the field. A comparison of competing models using the Akaike Information Criteria (AIC), found the best performance by the Conventional Distance Sampling (CDS) analysis engine, with the key function Hazard-Rate and series expansion Cosine

Two additional models were run to test the possibility of bias resulting from human disturbance and double counting of individuals at a point count. Human disturbance during surveys could cause the systematic movement of owls along transects, which would result in an over-estimate 
of population size. The model to assess this bias consisted of observations from only the first, centre (if the transect was longer than $600 \mathrm{~m}$ ), and last point counts of each transect to ensure that this subset of the data was from point counts that were at least $800 \mathrm{~m}$ apart. Based on the observed behaviour of scops owls, it was considered highly unlikely that birds would move this distance during a survey session of approximately three hours. The same model parameters as described above were applied to enable the comparison. The second model assessed the possibility of double counting of owls at a point by reducing the duration of the point counts to two minutes. We also analysed the last three minutes of the point count separately. This was achieved by splitting the observational data into two categories: $0-2$ minutes and $2-5$ minutes.

\section{Results}

\section{Field surveys}

Owls were recorded at 137 out of the $235(58 \%)$ point counts conducted in the dry season, and 131 out of $208(63 \%)$ of those conducted in the wet season. A total of 684 individual owls were recorded; 327 in the dry season and 357 in the wet season. Figure 1 shows the location of the recorded individuals. No owls were recorded in the mangrove forests. An extent of occurrence of $162.8 \mathrm{~km}^{2}$ was calculated using a minimum convex polygon from the observed presence data (Figure 2).

\section{Habitat associations}

Generalised linear models showed that the density of owls recorded in natural forest was significantly greater than degraded forest, agroforestry, and plantations. This result was the same for both seasons, but with the wet season showing the clearest difference in habitat associations (dry season: $P<0.0001, P<0.05, P<0.05, P<0.0001$, wet season $P<0.0001, P<0.01, P<0.01$, $P<0.0001$ ) (Figure 3).

\section{Niche suitability model}

The MaxEnt model was run with 289 presence points collected in the field, 86 of which were used for testing the performance of the model (rate of correct allocation of presence/absence). The results of the model are shown in Figure 2. The model performed well, with training AUC of 0.919 and test AUC of 0.902. Of the seven environmental variables, the permutation importance and jack- knife procedures with MaxEnt identified three variables as the most influential: distance from forest, elevation, and distance from roads and urban areas. The jack-knife results found the largest regularised training gain when only one of these variables was used and a decreased regularised training gain if these variables were removed. Thus, the probability of a suitable habitat was greatest at higher altitudes, shorter distances from forest, and larger distances from roads and urban areas.

\section{Population estimates}

The area of occupancy was calculated from the area of the 'high' suitability zone in the niche suitability model and was estimated to be $63 \mathrm{~km}^{2}$. During the dry season, owl density was estimated to be 0.55 individuals ha-1 (95\% CI: $0.42-0.72$ ) across this area, which gives a population size of 3,466 individuals ( $95 \%$ CI: $2,654-4,526$ ). For the wet season the owl density estimate was 0.87 individuals ha $\mathrm{h}^{-1}$ (95\% CI: $0.67-$ I.12), with a population size of 5,464 individuals (95\% CI: $4,232-7,054)$.

The results of the model designed to test the possibility of bias due to disturbance from surveys causing owl movements along transects, found a dry season owl density of 0.48 individuals ha- ${ }^{-1}$ 

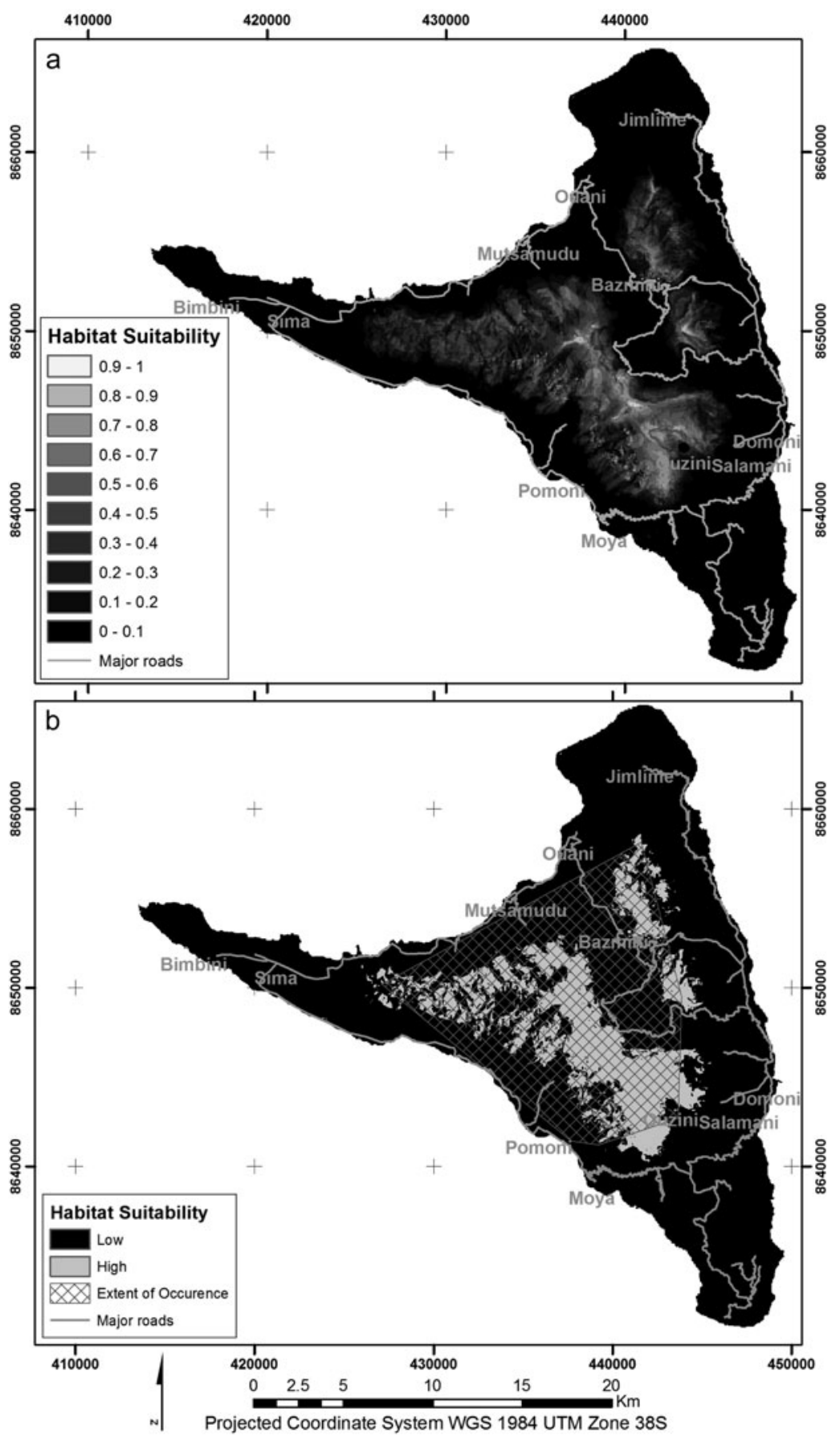

Figure 2. Map of predicted habitat suitability for Otus capnodes. Fig. Ia shows the probability output of the model and Fig za shows a binomial map of high and low habitat suitability produced, using the threshold probability of 0.34 , overlaid with the species' extent of occurrence calculated using a minimum convex polygon. 


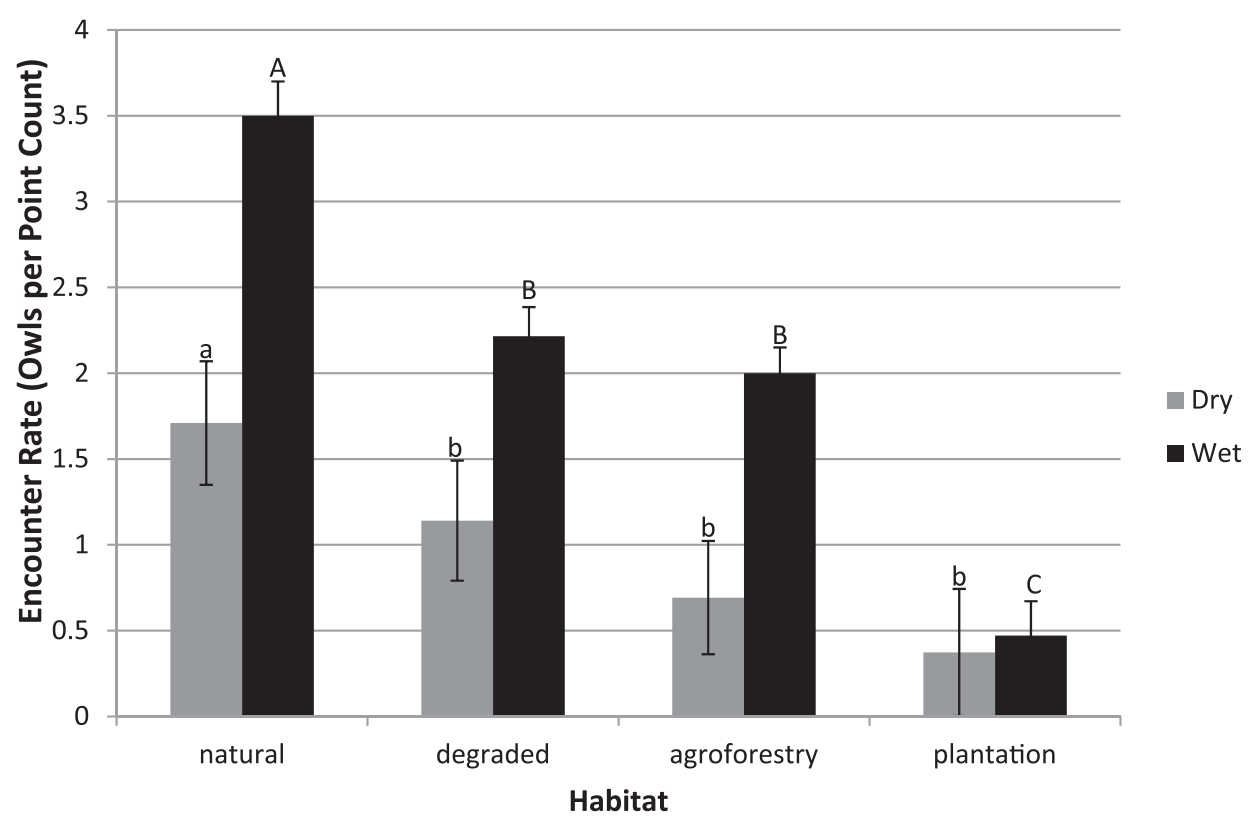

Figure 3. Encounter rate by season of Otus capnodes recorded during the passive listening phase of the point count. Differing letters show statistically significant differences. The comparison was analysed only within a season and not between the seasons, so the wet season results are shown in upper case letters, and the dry season shown in lower case.

(95\% CI: 0.37-0.61) and estimated population size of 2,999 (95\% CI: 2,355-3,820). During the wet season the owl density was estimated at 0.86 individuals ha-1 $(95 \%$ CI: 0.68-1.08) and estimated population size of 5,38I (95\% CI: 4,262-6,795).

The model designed to assess the possibility of double counting of individual owls at a point gave a dry season owl density of 0.52 individuals ha-1 $(95 \%$ CI: $0.37-0.72)$ with an estimated population size of 3,269 ( $95 \%$ CI: $2,355-4,538$ ), and a wet season owl density of o.8o individuals $\mathrm{ha}^{-1}$ (95\% CI: 0.60-1.08) with an estimated population size of 5,017 (95\% CI: 3,716-6,772). For the 2-5 minute point counts the analysis gave a dry season owl density of 0.43 individuals ha-1 (95\% CI: 0.30-0.59) with an estimated population size of 2,678 (95\% CI: 1,935-3,706), and a wet season owl density of 0.70 individuals ha-1 $(95 \%$ CI: 0.51-0.94) with an estimated population size of 5,623 (95\% CI: 4,157-7,604).

\section{Discussion}

The first comprehensive population survey of the 'Critically Endangered' O. capnodes confirms that the species is substantially more widely distributed and numerous than previously thought (Safford 1993, Moorcroft et al. 1995). We confirm that O. capnodes not only occurs in high elevation undisturbed forest but also in agroforestry zones and areas of forest with significant levels of disturbance, with observations of owls made as low as $300 \mathrm{~m}$. An extent of occurrence of $162.8 \mathrm{~km}^{2}$ was calculated and using the survey data and a range of remotely sensed data, we developed a niche suitability model which predicted an area of high suitability of $63 \mathrm{~km}^{2}$. This area covers the forest and agroforestry zones of the central highlands, away from the urban areas along the coasts.

The estimated population size was significantly higher than previous estimates; 3,450 owls in the dry season and 5,450 in the wet season. The analysis was conducted separately per season 
which found notable differences in population size. This disparity is likely to be a result of both the presence of juveniles and higher detection probability during the breeding season (Barnes and Belthoff 2008), thought to occur between August and December (Herremans et al. 1991, Goodman et al. 1993, Currie et al. 2004), when the wet season survey was conducted. Higher detection probability in the breeding season could have resulted from increased vocalisation frequency due to the presence of juveniles, mating pairs, and territorial males (Wilson and Bart 1985, McShea and Rappole 1997, Watson et al. 1999, Flesch and Steidl 2007) and/or heightened foraging activity (Drent and Daan 1980, Jönsson 1997).

Although both the dry and wet season population estimates are relatively similar to the estimated dry season population size of 4,950 individuals given in Lloyd (2010), they are markedly higher than the previous estimates of 50 to 200 individuals (Safford et al. 1993, Moorcroft et al. 1995). We consider our population estimates to be reliable for a number of important reasons. Firstly, due to the prior uncertainty about the distribution of the species, surveying was conducted over a wide area, including many areas which proved to be unoccupied. The niche suitability model's predicted area of high habitat suitability was then used to refine the survey area and data from only the point counts falling within this area were used in the analysis to ensure that the survey design was as efficient as possible. The refined survey area did not include a number of marginal areas of the species' distribution therefore the population estimates could be slightly biased downwards. Secondly, any possible double counting of owls at each point was minimised through short point count lengths of five minutes (Scott and Ramsay 1981, Fuller and Langslow 1984, Verner 1988), the presence of at least three observers, and by ensuring that owls that could potentially have been recorded more than once, as a result of movement, were removed from the analysis (Buckland et al. 1993, Thomas et al. 2010). We believe that these measures were effective given that the density estimates based on data from the reduced point count durations were very similar to those based on the 5 -minute point count. If repeated counting had occurred, the analysis of the reduced point count duration would be expected to show a significant reduction in estimated population size in one or both seasons. Thirdly, the population estimate from the model designed to test the possibility of survey-induced owl movement was very similar to the population estimates which used the whole dataset, implying that no bias occurred through systematic scops owl movement. If owls had moved between the point counts along the transect due to human disturbance, then use of data from point counts located far apart in the model would have led to a smaller population estimate. Fourthly, although the effects of background noise on auditory detection and distance estimations were low as point counts were conducted at night, the acoustics resulting from the steep terrain of Anjouan made it difficult to estimate the distance of individuals from the point (Pacifici et al. 2008; Simons et al. 2009). The effect of possible error in distance estimation was reduced by grouping the data into large distance intervals. Finally, O. capnodes was encountered at a high percentage of point counts in both seasons: $58 \%$ of point counts recording $O$. capnodes in the dry season and $63 \%$ of point counts in the wet season. Such high encounter rates for a nocturnal and cryptic species imply a large population size.

Although $O$. capnodes was recorded in modified habitats, encounter rates in natural forest, particularly in the wet season, were almost twice as high as in degraded forests and agroforestry zones and six times higher than in plantations. The importance of forest habitats for O. capnodes was further demonstrated by the niche suitability model which found 'distance from forest' to be a highly significant variable. This implies that areas within degraded forests and agroforestry zones are more suitable for $O$. capnodes if they are located close to undisturbed forest. This distribution could be a result of specific resources required by the species occurring primarily in natural relatively undisturbed forest, such as large native tree cavities for roosting (DeWalt et al. 2003, Monterrubio-Rico and Escalante-Pliego 2006, Cornelius et al. 2008). It could also be a consequence of lower anthropogenic disturbance (Herremans et al. 1991, Safford 1993, Currie et al. 2004, Martínez and Zuberogoitia 2004, Virani et al. 2010), with natural forest found at higher altitudes, at greater distances from urban areas, and in areas which are very difficult, if not impossible, to access. 
The high rates of deforestation which have occurred (FAO 2010) and are still occurring in Anjouan are of great threat to the survival of O. capnodes. This deforestation is driven by high demand for timber resources and agricultural land, limited land availability, lack of intensive agricultural methods, loss of soil fertility due to over exploitation and run-off, demographic pressures, poverty, and the lack of alternatives to agriculture (ECDD 2013). Consequently, there is enormous pressure upon the small area of unprotected native forest remaining, the key habitat for $O$. capnodes identified by this study. This reinforces the urgent need for habitat protection for this, and other, endemic species as recommended by BirdLife International (2008b).

The formation of a terrestrial protected area network for the Comoros Islands is in development and two zones in Anjouan have been proposed: Mount Ntringui and the Moya Forest (GEF 2012). However, this study has not only identified the need to protect the natural relatively undisturbed forest which is the key habitats for O. capnodes, but has demonstrated the importance of degraded forest and agroforestry zones for the species, particularly when in close proximity to the forest fragments. Given their highly modified nature, these areas are unlikely to be considered within the ongoing development of the Comoros terrestrial protected area network. This raises the importance of broader landscape management that takes into account the needs of biodiversity as well as people's livelihoods. In the Moya Forest zone, community-led integrated landscape management is ongoing (www.ecddcomoros.org) and O. capnodes habitat suitability, along with spatial information on other threatened and endemic Comorian biodiversity, such as the 'Endangered' Livingstone's fruit bat Pteropus livingstonii (B. M. Daniel et al. in litt.), are being used to identify zones of high conservation value. Yet these management plans require even further information for O. capnodes, in particular how its ecology relates to features of these anthropogenically modified habitats; such as tree size/density in relation to the availability of nest sites, and species diversity relating to the availability of prey. Given that modified habitats were found to be less important for the species than natural relatively undisturbed forest, further research is required to understand the cause of this distribution, whether the modified habitats provide the resources required by owls throughout the year, and the impact of habitat change on scops owl survival, fecundity and dispersal.

As found in this study, the difficulty in surveying and detecting scarce and elusive species may lead to them being categorised as extremely rare, when actually they are more numerous than believed. The elusive and nocturnal nature of $O$. capnodes, the challenging landscape, and inadequate survey effort had previously led to underestimation of the population and distribution of the species. The current study has provided information on the true status of the species through comprehensive field surveys complemented by niche suitability modelling. These results may have a bearing on the current IUCN Red List category assigned to O. capnodes. Although the main threats to the species resulting from deforestation are ongoing, the rate of population decline is probably not high enough to meet the criteria for 'Critically Endangered' and the geographic range and population size are clearly greater than the relevant thresholds for this category. The estimated extent of occurrence is greater than $100 \mathrm{~km}^{2}$ and the area of occupancy is greater than $10 \mathrm{~km}^{2}$, and under the IUCN Red List criterion B (IUCN 2012) O. capnodes should be considered for downlisting from 'Critically Endangered' to 'Endangered'. It is important to note that this does not represent an improvement in the status of this species but a development in the knowledge of the status of the species.

\section{Acknowledgements}

Funding for this study was provided by the Darwin Initiative of the UK government, the French Development Agency, the Global Environment Facility through the Programme of Work for Protected Areas, and BirdLife International's Preventing Extinctions Initiative. GIS software was provided by ESRI through Planet Action. We are grateful to all the guides for their assistance with the field work. Thanks to Mark O'Connell and Michael Hudson for their support with the analysis, and Peter Long and Mark $\mathrm{O}^{\prime}$ Connell for their comments on earlier drafts of the manuscript. 


\section{References}

Barnes, K. P. and Belthoff, J. R. (2008) Probability of detection of Flammulated owls using nocturnal broadcast surveys. J. Field Ornithol. 79: 321-328.

Benson, C. W. (1960) The birds of the Comoro Islands: results of the BOU centenary expedition. Ibis 103B: 5-106.

BirdLife International (2008a) State of the world's birds: indicators for our changing world. Cambridge, UK: BirdLife International.

BirdLife International (2008b) Critically Endangered birds: a global audit. Cambridge, UK: BirdLife International.

Buckland, S. T., Anderson, D. R., Burnham, K. P. and Laake, J. L. (1993) Distance sampling: estimating abundance of biological populations. London, UK: Chapman \& Hall.

Butchart, S. H. M. (2007) Birds to find: a review of 'lost', obscure and poorly known African bird species. Bulletin ABC 14: 139-157.

Cornelius, C., Cockle, K., Politi, N., Berkunsky, I., Sandoval, L., Ojeda, V., Rivera, L., Hunter, Jr., M. and Matin, K. (2008) Cavity-nesting birds in neotropical forests: cavities as a potentially limiting resource. Ornitol. Neotrop. 19: 253-268.

Currie, D., Fanchette, R., Millett, J., Hoareau, C. and Shah, N. J. (2004) The breeding biology of the Critically Endangered Seychelles Scops Owl Otus insularis: consequences for conservation and management. Bird Conserv. Internatn. 14: 123-137.

DeWalt, S. J., Maliakal, S. K. and Denslow, J. S. (2003) Changes in vegetation structure and composition along a tropical forest chronosequence: implications for wildlife. For. Ecol. Manage. 182: 139-151.

Doulton, H., Marsh, C., Newman, A., Bird, K. and Bell, M. (2006) Conservation Comoros 2005: biodiversity and resource-use assessment and environmental awareness, final report. Unpublished report.

Drent, R. H. and Daan, S. (1980) The prudent parent: energetic adjustments in avian breeding. Ardea 68: 225-252.

Eberhardt, L. L. (1968) A preliminary appraisal of line transects. J. Wildl. Manage. 32: 82-88.
Eberhardt, L. L. (1978) Transect methods for population studies. J. Wildl. Manage. 42: 1-31.

ECDD (2013) Rapport final provisoire du projet Engagement Communautaire pour le Developpement Durable (ECDD). Unpublished report.

FAO (2010) Global forest resource assessment 2010: Main report. Rome, Italy: Food and Agriculture Organisation, FAO Forestry Paper (Volume 163).

Flesch, A. D. and Steidl, R. J. (2007) Detectability and response rates of Ferruginous PygmyOwls. J. Wildl. Manage. 71: 981-990.

Fuchs, J., Pons, J. M., Goodman, S. M., Bretagnolle, V., Melo, M., Bowie, R. C. K., Currie, D., Safford, R., Virani, M. Z., Thomsett, S., Hija, A., Cruaud, C. and Pasquet, E. (2008) Tracing the colonization history of the Indian Ocean scops-owls (Strigiformes: Otus) with further insight into the spatio-temporal origin of the Malagasy avifauna. BMC Evol. Biol. 8: 197.

Fuller, R. J. and Langslow, D. R. (1984) Estimating numbers of birds by point counts: how long should counts last? Bird Study 31: 195-202.

GEF (2012) Global Environment Facility (GEF) project identification form. Unpublished report.

Gillison, A. N. and Brewer, K. R. W. (1985) The use of gradient directed transects or gradsects in natural resource surveys. J. Environ. Manage. 20: 103-127.

Goodman, S. M., Langrand, O. and Raxworthy, C. J. (1993) Food habits of the Madagascar long-eared owl Asio madascariensis in two habitats in southern Madagascar. Ostrich 64: 79-85.

Green, K. (2013) Land cover mapping of the Comoros Islands: methods and results. Unpublished report.

Gurney, J. H. (1889) On an apparently undescribed species of owl from Anjouan Island, proposed to be called Scops capnodes. Ibis 1: 104-107

Hernandez, P. A., Graham, C. H., Master, L. L. and Albert, D. L. (2006) The effect of sample size and species characteristics on performance of different species distribution modelling methods. Ecography 29: 773-785. 
Herremans, M., Louette, M. and Stevens, J. (1991) Conservation status and vocal and morphology description of the Grand Comoro Scops Owl Otus pauliani Benson 1960. Bird Conserv. Internatn. 1: 123-133.

IUCN (2012) IUCN Red List categories and criteria: version 3.1. Second Edition. Gland, Switzerland and Cambridge, UK: IUCN.

IUCN (2014) The IUCN Red List of threatened species. Version 2014.2. <www.iucnredlist. org>

Jönsson, K. I. (1997) Capital and income breeding as alternative tactics of resource use in reproduction. Oikos 78: 57-66

Lafontaine, R. M. and Moulaert, N. (1998) Une nouvelle espèce de petit-duc (Otus, Aves) aux Comores: taxonomie et statut de conservation. J. African Zool. 112: 163-169.

Lloyd, S. P. (2010) Habitat suitability modelling for the Anjouan Scops Owl, A cryptic and unstudied species. Unpublished MSc thesis, Imperial College London.

Martínez, J. A. and Zuberogoitia, Í. (2004) Habitat preferences and causes of population decline for barn owls Tyto Alba: a multi-scale approach. Ardeola 51: 303-317.

McShea, W. J. and Rappole, J. H. (1997) Variable song rates in three species of passerines and implications for estimating bird populations. J. Field Ornithol. 68: $367-375$.

Miranda, H. C., Brooks, D. M. and Kennedy, R. S. (2011) Phylogeny and taxonomic review of the Philippine lowland scops owls (Strigiformes): parallel diversification of highland and lowland clades. Wilson J. Ornithol. 123: 441-453.

Monterrubio-Rico, T. C. and Escalante-Pliego, P. (2006) Richness, distribution and conservation status of cavity nesting birds in Mexico. Biol. Conserv. 128: 67-78.

Moorcroft, D., Stansfield, S., Hacker, M., Shaw, D., Young, C. and Palmer, N. (1995) Final report of the Newcastle University Anjouan Expedition. Unpublished report.

Pacifici, J. K., Simons, T. R. and Pollock, K. H. (2008) Effects of vegetation and background noise on the detection process in auditory avian point-count surveys. Auk 125: 600-607.

Pearson, R. G., Raxworthy, C. J., Nakamura, M. and Townsend Peterson, A. (2007) Predicting species distributions from small numbers of occurrence records: a test case using cryptic geckos in Madagascar. J. Biogeogr. 34: 102-117.

Philips, S. J., Anderson, R. P. and Schapire, R. E. (2006) Maximum entropy modelling of species geographic distributions. Ecol. Modell. 190: 231-259.

Ralph, C. J. and Scott, J. M (1981) Estimating numbers of terrestrial birds. Lawrence, Kansas: Cooper Ornithological Society. (Studies in Avian Biology No.6).

Ralph, C. J., Sauer, J. R. and Droege, S. (1995) Monitoring bird populations by point counts. Albany, CA: US Forest Service. (Gen. Tech. Rep. PSW-GTR-149).

Rasmussen, P. C, Schulenberg, T. S., Hawkins, F. and Voninavoko, R. (200o) Geographic variation in the Malagasy scops-owl (Otus rutilus auct.): the existence of an unrecognized species on Madagascar and the taxonomy of the other Indian Ocean taxa. Bull. Brit. Ornithol. Club 120: 75-102.

Rempel, R. S., Kaukinen, D. and Carr, A. P. (2012) Patch analyst and patch grid. Thunder Bay, Ontario: Centre for Northern Forest Ecosystem Research, Ontario Ministry of Natural Resources.,

$\mathrm{R}$ Core Development Team (2010) R: A language and environment for statistical computing. [2.11.1] Vienna, Austria: R Foundation for Statistical Computing.

Safford, R. J. (1993) Rediscovery, taxonomy, and conservation of the Anjouan Scops Owl Otus capnodes (Gurney 1889). Bird Conserv. Internatn. 3: 57-74.

Scott, J. M. and Ramsay, F. L. (1981) Length of count period as a possible source of bias in estimating bird densities. Stud. Avian Biol. 6: 409-413.

Simons, T. R, Alldredge, M. W., Pollock, K. H. and Wettroth, J. M. (2009) Experimental analysis of the auditory detection process on avian point counts. Auk 124: 986-999.

Thomas, L., Buckland, S. T., Rexstad, E. A., Laake, J. L., Strindberg, S., Hedley, S. L., Bishop, J. R. B., Marques, T. A. and Burnham, K. P. (2010) Distance software: design and analysis of distance sampling surveys for estimating population size. J. Appl. Ecol. 47: 5-14. 
Tobias, J. A., Butchart, S. H. M. and Collar, N. J. (2006) Lost and found: a gap analysis for the Neotropical avifauna. Neotrop. Birding 1: 4-22.

UN (2010) Country profiles for population and reproductive health. New York: United Nations Population Fund and Population Reference Bureau (www.unfpa. org/countries).

UNEP (2008) Africa: atlas of our changing environment. Nairobi, Kenya: United Nations Environmental Programme, Division of Early Warning and Assessment (DEWA).

Verner, J. (1988) Optimizing the duration of point counts for monitoring trends in bird populations. Albany, California: US Forest Service, Pacific Southwest Station. (General technical report PSW - 395).

Vié, J. C., Hilton-Taylor, C. and Stuart, S. N. (eds.) (2009) Wildlife in a changing world: An analysis of the 2008 IUCN Red List of threatened species. Gland, Switzerland and Cambridge. UK: IUCN.
Virani, M. Z., Njoroge, P. and Gordon, I. (2010) Disconcerting trends in populations of the endangered Sokoke Scops Owl Otus ireneae in the Arabuko-Sokoke Forest, Kenya. Ostrich 81: 155-158.

Watson, J. W., Hays, D. W. and Pierce, D. J. (1999) Efficacy of Northern Goshawk broadcast surveys in Washington state. J. Wildl. Manage. 63: 98-106.

Widodo, W., Cox, J. H. and Rasmussen, P. C. (1999) Rediscovery of the Flores Scops Owl Otus alfredi on Flores, lesser Sunda Islands, Indonesia, and reaffirmation of its specific status. Forktail 15: 15-23.

Wlison, D. M. and Bart, J. (1985) Reliability of singing bird surveys: effects of song phenology during the breeding season. The Condor 87: 69-73.

Wisz, M. S., Hijmans, R. J., Li, J., Peterson, A. T., Graham, C. H., Guisan, A. and NCEAS Predicting Species Distributions Working Group (2008) Effects of sample size on the performance of species distribution models. Divers. Distrib. 14: 763-773.

\section{KATHLEEN E. GREEN*}

Bristol Zoological Society, Bristol Zoo Gardens, Clifton, Bristol, BS8 3 HA, UK.

HUGH DOULTON, ISHAKA SAID, AMELAID HOUMADI, DANIEL M. SALIM

Dahari, Hombo-Mutsamudu, Anjouan, Union des Comores.

\section{SOUFIANI M'MADI}

Université des Comores, Route de la Corniche, Moroni, Union des Comores.

\section{SAMUEL P. LLOYD}

Imperial College London, South Kensington Campus, London SW7 2AZ, UK.

\section{BRONWEN M. DANIEL, RICHARD P. YOUNG}

Durrell Wildlife Conservation Trust, Les Augrès Manor, La Profonde Rue, Trinity, Jersey, Channel Islands, JE3 5 BP, UK.

*Author for correspondence; email: katiegreenuk@gmail.com 